\title{
Is Inflammation Related to the Clinical Severity of Unstable Angina?
}

\author{
Sunao Kojima, MD; Hiroshi Nonogi, MD; Isao Morii, MD; \\ Hitoshi Sumida, MD; Yasuo Sutani, MD; Satoshi Yasuda, MD; \\ Satoshi Daikoku, MD; Yoichi Goto, MD; Shunichi Miyazaki, MD
}

\begin{abstract}
The present study determined the white blood cell (WBC) count and the serum C-reactive protein (CRP) level in 27 patients with coronary spastic angina, 16 with Braunwald class IB unstable angina (UA) and 13 with Braunwald class IIIB. The relationship between the clinical presentation of UA and the requirement for emergency percutaneous transluminal coronary angioplasty (PTCA) was examined, and in patients with medically refractory angina, the determining factor among the clinical manifestations of angina was also investigated. In the acute phase, the WBC count and the serum CRP level were significantly higher in patients with Braunwald class IIIB than in those with coronary spastic angina or Braunwald class IB UA $(p<0.001)$. In the Braunwald class IIIB group, a significantly higher rate of patients required emergency PTCA than that of the coronary spastic angina group $(\mathrm{p}<0.01)$. Patients with medically refractory angina had a significantly higher WBC count and higher serum CRP level on admission, and the WBC count on admission was independently associated with medically refractory angina by multivariate analysis $(\mathrm{p}<0.05)$. Inflammation may play a major pathological role in the rapid development of acute coronary syndrome. (Jpn Circ J 2001; 65: 414-418)
\end{abstract}

Key Words: C-reactive protein; Medically refractory angina; Unstable angina; White blood cells

$\mathbf{T}$ he clinical manifestation of stable angina depends on the presence of advanced coronary atherosclerosis, which predictably causes a reduction in myocardial oxygen supply relative to myocardial oxygen demand! In contrast, acute coronary syndrome, such as unstable angina (UA) or acute myocardial infarction, is unpredictable and caused by a coronary flow obstruction, which can be due to different pathophysiological mechanisms, such as increased vasomotor tone or thrombus formation following coronary plaque rupture or plaque erosion? ${ }^{2-11}$ Inflammation is an important feature of atherosclerotic lesions ${ }^{12}$ and increased production of C-reactive protein (CRP) is associated with a poor prognosis in cases of severe UA $!^{3-19}$ However, the relationship between the levels of the inflammatory parameter and the clinical presentations of UA has not been investigated extensively. Therefore, we determined the white blood cell (WBC) count and serum CRP level in patients with UA and examined the features of cases that were medically refractory.

\section{Methods}

\section{Patient Selection}

Fifty-six patients with UA (41 men, 15 women; mean age, $62 \pm 9$ years) admitted to the coronary care unit in the National Cardiovascular Center were considered eligible to enter the study. Unstable angina was clinically defined as

(Received November 27, 2000; revised manuscript received January 16, 2001; accepted February 7, 2001)

Division of Cardiology, Department of Medicine, National Cardiovascular Center, Osaka, Japan

Mailing address: Hiroshi Nonogi, MD, Division of Cardiology, Department of Medicine, National Cardiovascular Center, 5-7-1 Fujishiro-dai, Suita, Osaka 565-8565, Japan. E-mail: hnonogi@ @sp. ncvc.go.jp angina in patients at rest, new-onset angina, or accelerated angina caused by exertion of effort within the previous $48 \mathrm{~h}$, without development of abnormal Q waves on the ECG and elevation of the serum creatine kinase level to no more than twice the upper normal limit. It was the first episode of ischemic heart disease for these patients and they had never been previously treated with any combinations of aspirin, nitrates, $\beta$-blockers and/or calcium antagonists before blood sampling. The criterion for inclusion in this study was 0 - or 1-vessel involvement, and the criterion for exclusion was the presence of inflammatory diseases, other than ischemic heart disease, on admission.

\section{Clinical Characteristics}

Clinical characteristics and laboratory findings were assessed from the medical records of each patient. Unstable angina was classified into 3 categories based on coronary angiography (CAG): coronary spasm, Braunwald IB and Braunwald class IIIB. Incremental doses of ergonovine or acetylcholine were injected into the coronary artery to provoke coronary spasm, which was defined as total or subtotal occlusion of the epicardial coronary arteries associated with signs of myocardial ischemia such as chest pain and ischemic ST segment changes; Braunwald class IB was defined as accelerated angina without pain at rest with a significant organic stenosis of the epicardial coronary artery ( $\geq 75 \%$ based on the American Heart Association (AHA) classification ${ }^{20}$ ); and Braunwald class IIIB was defined as angina at rest with a significant organic stenosis of the epicardial coronary artery ( $\geq 75 \%$ based on the AHA classification). Medically refractory angina was defined as angina unresponsive to initial therapy that included bed rest and administration of oxygen, aspirin, heparin, nitrates, $\beta$ adrenoreceptor blocking drugs, and/or calcium antagonists. Emergency percutaneous transluminal coronary angioplasty 
Table 1 Clinical Characteristics

\begin{tabular}{lccc}
\hline \hline & $\begin{array}{c}\text { Spasm } \\
(n=27)\end{array}$ & $\begin{array}{c}\text { Class IB } \\
(n=16)\end{array}$ & $\begin{array}{c}\text { Class IIIB } \\
(n=13)\end{array}$ \\
\hline Age (years) & $60 \pm 9$ & $65 \pm 10$ & $62 \pm 8$ \\
Male/female & $21 / 6$ & $11 / 5$ & $9 / 4$ \\
Incidence of hypertension (\%) & 44 & 50 & $85^{*}$ \\
Incidence of diabetes mellitus $(\%)$ & 11 & $50^{*}$ & 23 \\
Incidence of hypercholesterolemia $(\%)$ & 22 & 44 & $62 *$ \\
Body mass index $\left(\mathrm{kg} / \mathrm{m}^{2}\right)$ & $23 \pm 3$ & $23 \pm 3$ & $23 \pm 2$ \\
Incidence of current smoking habit $(\%)$ & 63 & 50 & 62 \\
\hline
\end{tabular}

Data are expressed as mean $\pm S D . * p<0.05$ relative to the values obtained in the spasm group.

(PTCA) was defined as coronary balloon angioplasty and/or coronary stenting performed within $24 \mathrm{~h}$ of admission for a significantly severe organic stenosis of the epicardial coronary artery ( $\geq 90 \%$ based on the AHA classification) detected by CAG. The surgeons were unaware of the patient's clinical characteristics and clinical data.

The presence or absence of risk factors for coronary artery disease was determined. Hypertension was considered to be present when long-term treatment had been administered or was required; diabetes mellitus was the diagnosis if a previous physician had prescribed dietary treatment with insulin or oral hypoglycemic agents; hypercholesterolemia was defined as a total serum cholesterol of at least $220 \mathrm{mg} / \mathrm{dl}$; smokers were defined as those currently smoking; the body mass index, as a reference index of obesity, was defined as weight divided by the square of the height $\left(\mathrm{kg} / \mathrm{m}^{2}\right)$. Other clinical characteristics and laboratory findings were determined on admission.

\section{Blood Sampling and Measurement of the Serum CRP Level}

Blood samples were collected from the patients with UA on admission and in the chronic phase. The WBC count was determined on a sample of venous blood using an automated blood cell counter. The quantitative serum CRP level (N Latex CRP Reagents) was measured with the Behring BN II Nephelometer (Behringwerke AG Marburg, Germany) in which polystyrene particles coated with monoclonal antibodies against CRP are agglutinated when mixed with samples containing CRP. The intensity of scattered light is proportional to the size of the aggregates and thus reflects the concentration of CRP present in the sample. Patient samples were automatically diluted 1:400 with N Diluent by the Behring Nephelometer and assayed within 4h. The N Latex CRP Kit is designed to measure CRP concentrations within a range of approximately $0.25-16$ $\mathrm{mg} / \mathrm{dl}$ with a sample dilution of 1:400. The coefficients of variation obtained for determinations of 3 different CRP concentrations $(\approx 1.9,3.7,7.5 \mathrm{mg} / \mathrm{dl})$ with the kit in 8 different series of triplicate assays were $2.2 \%, 2.4 \%$ and $2.2 \%$ for within-series precision and $10.8 \%, 9.8 \%$ and $9.4 \%$ for reproducibility. The lower detection limit was $0.3 \mathrm{mg} / \mathrm{dl}$ in the current study.

\section{Statistical Analyses}

Numerical data are presented either as mean \pm SD or percentages, unless otherwise noted. Group comparisons were performed using a one-way factorial ANOVA and multiple comparison tests. For multivariate analysis, significant variables obtained by univariate analysis were analyzed by multiple logistic regression analysis. A value of $p<0.05$

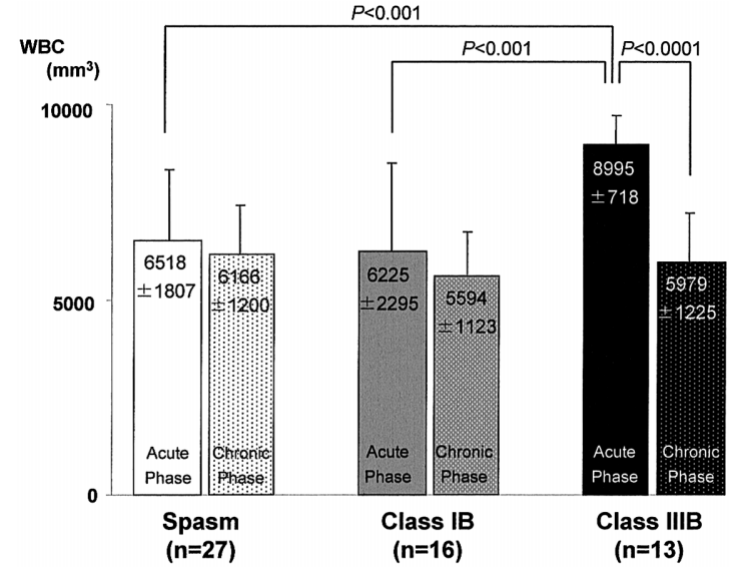

Fig 1. White blood cell (WBC) count in patients in the acute and chronic phases. Patients with Braunwald class IIIB unstable angina had a significantly higher WBC count than those with coronary spastic angina or Braunwald class IB unstable angina in the acute phase. WBC count in Braunwald class IIIB group in the acute phase is significantly higher than that in the chronic phase.

was considered significant.

\section{Results}

There were 27 patients in the coronary artery spasm group, 16 in the Braunwald class IB group and 13 in the Braunwald class IIIB group. The age, gender, body mass index and percent of current smokers were not significantly different among the 3 groups. The incidence of both hypertension and hypercholesterolemia was significantly higher in the Braunwald class IIIB group than in the coronary artery spasm group. The incidence of diabetes mellitus was significantly higher in the Braunwald class IB group than in the coronary artery spasm group (Table 1 ).

\section{Clinical Severity of Unstable Angina and Inflammation}

The patients in the Braunwald class IIIB group had a significantly higher WBC count on admission than those in the coronary artery spasm group or Braunwald class IB group; however, there were no significant differences in WBC count among the 3 groups in the chronic phase. In the Braunwald class IIIB group, the WBC count of patients on admission was significantly higher than that in the chronic phase (Fig 1).

In the acute phase, the incidence of serum CRP $\geq 0.3 \mathrm{mg} / \mathrm{dl}$ on admission was significantly higher in the Braunwald class IIIB group than in the coronary artery spasm group or Braunwald class IB group (Fig 2, Table 2); however, all 
patients in the chronic phase had the serum $\mathrm{CRP}<0.3 \mathrm{mg} / \mathrm{dl}$.

The incidence of medically refractory angina was higher in the Braunwald class IIIB group than in the coronary artery spasm group or Braunwald class IB group (Table 2). Emergency PTCA was performed in all patients with medically refractory angina caused by a coronary stenosis of more than $90 \%$ at the culprit lesion as determined by emergency CAG. None of the patients with UA developed acute myocardial infarction or died after admission. The average time from the onset of anginal attack to hospital admission was not significantly different among the 3 groups (coronary

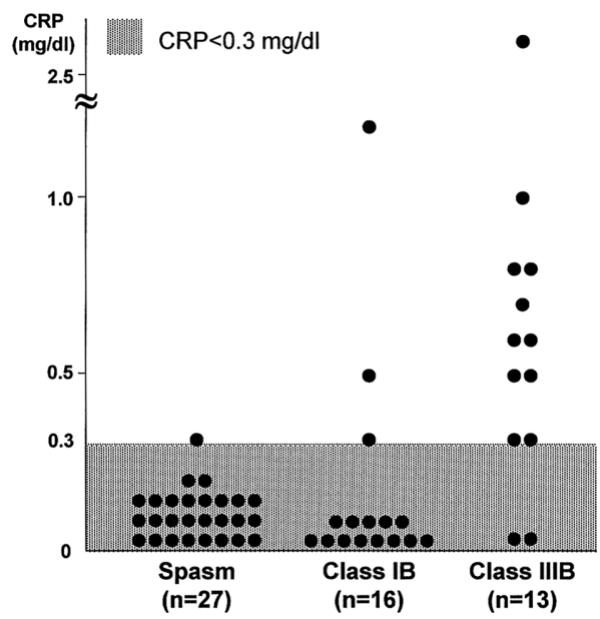

Fig 2. Scatter diagrams show the serum C-reactive protein (CRP) in the acute phase. artery spasm group: $11.7 \pm 12.6 \mathrm{~h}$; Braunwald class IB group: 15.8 $\pm 17.2 \mathrm{~h}$; and Braunwald class IIIB group: 19.9 $\pm 17.2 \mathrm{~h}$ ).

All patients with UA were divided into 2 groups: medically controlled angina (MCA; $n=50)$ and medically refractory angina (MRA; $n=6)$ and the following were compared: age, gender, body mass index, levels of total cholesterol, triglycerides and high-density lipoprotein concentration, WBC count and serum CRP level $(\geq 0.3 \mathrm{mg} / \mathrm{dl})$ on admission, the incidence of hypertension and diabetes mellitus and current smoking habit. A comparison of the clinical status of UA (coronary artery spasm + Braunwald class $\mathrm{IB}=0$, Braunwald class IIIB $=1$ ) was also performed. The WBC count and the incidence of serum CRP $\geq 0.3$ $\mathrm{mg} / \mathrm{dl}$ on admission, and Braunwald class IIIB UA were found to be significantly different between the MCA and MRA groups by univariate analysis, and the WBC count on admission was independently associated with medically refractory angina by multivariate analysis $(\mathrm{p}<0.05)$ (Table 3$)$.

\section{Discussion}

Inflammation is an important feature of atherosclerosis and, on the basis of histological findings, including the activation and proliferation of macrophages, endothelial cells, smooth-muscle cells, and generation of many kinds of cytokines and growth factors, ${ }^{21}$ may also be important in the pathogenesis of acute coronary syndrome. Inflammation may contribute to the weakening of the atherosclerotic plaque and to the rupture of the fibrous cap, with subsequent exposure of the lipid core to circulating blood components, resulting in coronary thrombosis 15

Acute coronary syndrome is caused by a coronary flow obstruction, which can be due to different pathophysiologi-

Table 2 Serum CRP Level and Medically Refractory Angina Incidence

\begin{tabular}{lccc}
\hline \hline & $\begin{array}{c}\text { Spasm } \\
(n=27)\end{array}$ & $\begin{array}{c}\text { Class IB } \\
(n=16)\end{array}$ & $\begin{array}{c}\text { Class IIIB } \\
(n=13)\end{array}$ \\
\hline Incidence of serum CRP $\geq 0.3 \mathrm{mg} / \mathrm{dl}(\%)$ & 4 & 19 & $85^{* \dagger}$ \\
Incidence of medically refractory angina $(\%)$ & 0 & 6 & $38^{*}$ \\
\hline
\end{tabular}

$C R P, C$-reactive protein. ${ }^{*} p<0.0001$ relative to the values obtained in the spasm group and ${ }^{\dagger} p<0.001$ relative to the values obtained in the class IB group. ${ }^{\ddagger} p<0.01$ relative to the values obtained in the spasm group and ${ }^{\sharp} p=0.06$ relative to the values obtained in the class IB group.

Table 3 Clinical Characteristics and Laboratory Findings in Patients With Medically Controlled or Medically Refractory Angina

\begin{tabular}{|c|c|c|c|c|}
\hline & \multirow{2}{*}{$\begin{array}{c}M C A \\
(n=50)\end{array}$} & \multirow{2}{*}{$\begin{array}{l}M R A \\
(n=6)\end{array}$} & \multicolumn{2}{|c|}{$p$ value } \\
\hline & & & Univariate & Multivariate \\
\hline Age (years) & $62 \pm 9$ & $63 \pm 8$ & NS & \\
\hline Male/female & $38 / 12$ & $3 / 3$ & NS & \\
\hline Incidence of hypertension (\%) & 54 & 67 & $N S$ & \\
\hline Incidence of diabetes mellitus (\%) & 24 & 33 & NS & \\
\hline Total cholesterol concentration $(\mathrm{mg} / \mathrm{dl})$ & $201 \pm 42$ & $225 \pm 35$ & NS & \\
\hline Triglyceride concentration $(\mathrm{mg} / \mathrm{dl})$ & $126 \pm 59$ & $161 \pm 92$ & NS & \\
\hline HDL concentration $(\mathrm{mg} / \mathrm{dl})$ & $48 \pm 16$ & $49 \pm 9$ & $N S$ & \\
\hline Body mass index $\left(\mathrm{kg} / \mathrm{m}^{2}\right)$ & $23 \pm 3$ & $24 \pm 2$ & $N S$ & \\
\hline Incidence of current smoking habit (\%) & 62 & 33 & NS & \\
\hline WBC count $\left(/ \mathrm{mm}^{3}\right)$ & $6,684 \pm 1,813$ & $9,855 \pm 2,100$ & 0.0002 & 0.04 \\
\hline Incidence of serum $C R P \geq 0.3 \mathrm{mg} / \mathrm{dl}(\%)$ & 20 & 83 & 0.004 & 0.08 \\
\hline Clinical status of UA (Spasm + Class IB/Class IIIB) & $42 / 8$ & $1 / 5$ & 0.002 & \\
\hline
\end{tabular}

MCA, medically controlled angina; MRA, medically refractory angina; HDL, high-density lipoprotein; WBC, white blood cells; CRP, $C$-reactive protein; UA, unstable angina; NS, not significant. Data are expressed as mean $\pm S D$. p<0.05 is considered statistically significant. 
cal mechanisms, including platelet aggregation, thrombus formation or increased vasomotor tone following coronary plaque rupture or plaque erosion.-11 More than $10 \%$ of patients with UA are liable to develop acute myocardial infarction,22,23 and the Braunwald classification grades patients with UA from the mildest to the most severe?4 Recurrent ischemia, which progresses to infarction or death, is more frequently observed in Braunwald class III UA than in Braunwald class I or class II; ${ }^{25}$ therefore, the conflicting results can be explained by the inclusion in the study of patients with different severities of unstable angina.

Berk et al found increased serum CRP levels in patients with UA compared with those with stable angina ${ }^{26}$ but there have not been any reports on the relationship between inflammation and clinical severity among patients with UA graded by the Braunwald classification. In the present study, patients with Braunwald class IIIB UA had a higher WBC count and serum CRP level on admission than those with coronary artery spasm or Braunwald class IB UA.

\section{Clinical Severity of Unstable Angina and Leukocytosis}

The WBC count has been found to be strongly related to the risk, extent and severity of coronary heart diseases. ${ }^{27-29}$ Friedman et al reported that the WBC count prior to acute myocardial infarction was markedly related to the development of infarction 28 Granulocytes in the stable form of coronary artery disease may activate platelets, predisposing the patient to the development of acute ischemic coronary syndromes ${ }^{30}$ through leukocyte stimulation, which results in the release of platelet-activating factors and chemotactic and vasospastic substances (eg, leukotriens and thromboxanes) ${ }^{31}$ In patients with UA at rest, there is a relationship with the degree of neutrophil activation within $48 \mathrm{~h}$ of $\mathrm{CAG}^{32}$ and the increased thrombin formation caused by the expression of a tissue-factor like activity by activated monocytes ${ }^{33} \mathrm{~A}$ higher than normal WBC count in Braunwald class III patients may be an indicator of subsequent major cardiac events because resting patients with acute angina are likely to develop recurrent angina or acute myocardial infarction.5 Patients with acute myocardial infarction involving coronary plaque rupture have a significantly higher WBC count and a higher incidence of preinfarction UA, suggesting that patients with preinfarction angina are more responsive to the inflammatory stimuli caused by myocardial necrosis and reperfusion 34 In the present study, the WBC count on admission was not significantly different between the coronary artery spasm and Braunwald class IB groups, but a significantly higher WBC count on admission and a higher incidence of medically refractory angina were observed in patients with Braunwald class IIIB. Therefore, Braunwald class IIIB unstable angina may be related to a higher WBC count and may predict major cardiac events such as medically refractory angina and acute myocardial infarction. Moreover, in patients with Braunwald class IIIB UA, the WBC count on admission was significantly higher than in the chronic phase, indicating that the WBC may affect unstable coronary plaque or may reflect the pathophysiological condition of such patients.

\section{Clinical Severity of Unstable Angina and Serum CRP Levels}

The production of CRP during acute-phase angina is a nonspecific phenomenon reflecting cytokine-mediated hepatic production triggered by most forms of inflammation, infection and tissue injury ${ }^{13-15}$ The serum CRP level starts to rise approximately $6 \mathrm{~h}$ after an acute stimulation and reaches a peak within approximately $48 \mathrm{~h}$. After an abrupt cessation of the stimulation, values decrease exponentially at a rate close to the measured half-life of serum CRP of approximately $19 \mathrm{~h} \cdot 15,35-37$ Oltrona et al have shown that many patients with Braunwald class IIIB UA have abnormally increased serum CRP levels on admission, ${ }^{14}$ which we also found. The serum CRP level may increase before the onset of the anginal attack in the Braunwald class IIIB group and the pathological mechanism may be different between coronary artery spasm and Braunwald class IB UA. Plaque rupture per se is not the main cause of the increase in the serum CRP level at the onset of Braunwald class IIIB UA, ${ }^{38}$ nor are episodes of ischemiareperfusion sufficient to cause increased CRP production, 37 and the systemic elevation of markers of thrombin production is not followed by an increase in CRP 39 The present study has revealed that the increase in serum CRP levels is not a secondary result of myocardial necrosis; therefore, an enhanced inflammatory response to nonspecific stimuli may be related to the pathogenesis, and an acute inflammatory stimuli may be related to the increase in the serum CRP level, which occurs before the onset of an anginal attack.

Serum CRP levels in patients with UA may be used as a long- or short-term prognostic value ${ }^{13-19}$ When the serum $\mathrm{CRP}$ is $0.3 \mathrm{mg} / \mathrm{dl}$ on admission, there are significantly more recurrent episodes of angina at rest, despite therapy, including intravenous administration of nitrates and heparin, and a higher incidence of myocardial revascularization than those patients whose serum CRP $<0.3 \mathrm{mg} / \mathrm{dl}$ on admission 13 In the present study, patients with Braunwald class IIIB UA had a significantly higher incidence of medically refractory angina; emergency PTCA was performed in 38\% of these patients compared with $6 \%$ of patients with Braunwald class IB UA. Quantification of serum CRP levels was not done in the present study, but Liuzzo et al have shown that when serum $\mathrm{CRP} \geq 0.3 \mathrm{mg} / \mathrm{dl}$ on admission there is a poor outcome in patients with UA 13

In summary, the onset mechanism of Braunwald class IIIB UA may be different from that of coronary artery spastic angina or Braunwald class IB UA, and inflammation may be related to its development.

\section{Study Limitations}

This study is limited by the relatively small number of patients included. WBC and CRP are acute-phase substances and increase with non-specific inflammatory processes. However, the inclusion and exclusion criteria were firm and all patients were consecutively enrolled. Patients with Braunwald class IIIB UA had a significantly higher WBC count and elevated serum CRP level on admission, which may be a strong indicator of medically refractory angina and/or the composition of the coronary plaque.

\section{Clinical Implications}

These findings suggest that inflammation may play a major pathophysiological role in the rapid development of acute coronary syndrome. A higher WBC count and elevated serum CRP level on admission in patients with Braunwald class IIIB UA appear to be indicative of the requirement for emergency coronary intervention.

\section{References}

1. Gersh BJ, Braunwald E, Rutherford JD: Stable angina pectoris. In: 
Braunwald E, editor. Heart disease: a textbook of cardiovascular medicine, 5th edn. Philadelphia: W.B. Saunders, 1997: 1290-1313

2. Burke AP, Farb A, Malcom GT, Liang Y, Smialek J, Virmani R: Coronary risk factors and plaque morphology in men with coronary disease who died suddenly. N Engl J Med 1997; 336: 1276-1282

3. Report of a meeting of physicians and scientists, Texas Heart Institute and the University of Texas Medical School at Houston: Thrombus and unstable angina. Lancet $1993 ; \mathbf{3 4 2}$ : $1151-1155$

4. Farb A, Burke AP, Tang AL, Liang Y, Mannan P, Smialek J, et al: Coronary plaque erosion without rupture into a lipid core: A frequent cause of coronary thrombosis in sudden coronary death. Circulation 1996; 93: $1354-1363$

5. Davies MJ: Stability and instability: Two faces of coronary atherosclerosis (The Paul Dudley White Lecture 1995). Circulation 1996; 94: $2013-2020$

6. Falk E, Shah PK, Fuster V: Coronary plaque disruption. Circulation 1995; 92: 657-671

7. Fuster V, Lewis A: Conner Memorial Lecture: Mechanisms leading to myocardial infarction: Insights from studies of vascular biology. Circulation 1994; 90: 2126-2146

8. Muller JE, Abela GS, Nesto RW, Tofler GH: Triggers, acute risk factors and vulnerable plaques: The lexicon of a new frontier. $J A m$ Coll Cardiol 1994; 23: 809-813

9. Kristensen SD, Ravn HB, Falk E: Insights into the pathophysiology of unstable coronary artery disease. Am J Cadiol 1997; 80: 5E-9E

10. Shah PK, Forrester JS: Pathophysiology of acute coronary syndromes. Am J Cardiol 1991; 68: 16C-23C

11. Thèroux P: A pathophysiologic basis for the clinical classification and management of unstable angina. Circulation 1987; 75(Suppl V): V-103-V-109

12. Soeki T, Tamura Y, Shinohara H, Tanaka H, Bando K, Yui Y, et al: Fibrinolytic factors, serum lipid and $\mathrm{C}$-reactive protein predicting cardiac events in Japanese patients with coronary atherosclerotic lesions. Jpn Circ J 1999; 63: 976-980

13. Liuzzo G, Biasucci LM, Gallimore R, Grillo RL, Rebuzzi AG, Pepys $\mathrm{MB}$, et al: The prognostic value of $\mathrm{C}$-reactive protein and serum amyloid: A protein in severe unstable angina. N Engl J Med 1994; 331: $417-424$

14. Oltrona L, Ardissino D, Merlini PA, Alessandra S, Chiodo F, Pezzano A: C-reactive protein elevation and early outcome in patients with unstable angina pectoris. Am J Cardiol 1997; 80: $1002-1006$

15. Mach F, Lovis C, Gaspoz JM, Unger PF, Bouillie M, Urben P, et al: $\mathrm{C}$-reactive protein as a marker for acute coronary syndromes. Eur Heart J 1997; 18: 1897-1902

16. Benamer H, Steg PG, Benessiano J, Vicaut E, Gaultier CJ, Boccara $\mathrm{A}$, et al: Comparison of the prognostic value of $\mathrm{C}$-reactive protein and troponin I in patients with unstable angina pectoris. Am J Cardiol 1998; 82: $845-850$

17. Morrow DA, Rifai N, Antman EM, Weiner DL, McCabe CH, Cannon $\mathrm{CP}$, et al: C-reactive protein is a potent predictor of mortality independently of and in combination with troponin $\mathrm{T}$ in acute coronary syndromes: A TIMI 11A substudy. J Am Coll Cardiol 1998; 31: 1460- 1465

18. Toss H, Lindahl B, Siegbahn A, Wallentin L, for the FRISK study group: Prognostic influence of increased fibrinogen and C-reactive protein levels in unstable coronary artery disease. Circulation 1997; 96: $4204-4210$

19. Rebuzzi AG, Quaranta G, Liuzzo G, Caligiuri G, Lanza GA, Gallimore JR, et al: Incremental prognostic value of serum levels of troponin $\mathrm{T}$ and $\mathrm{C}$-reactive protein on admission in patients with unstable angina pectoris. Am J Cardiol 1998; 82: 715-719

20. Report of the Ad Hoc Committee for Grading of Coronary Artery
Disease, Council on Cardiovascular Surgery, American Heart Association: A reporting system on patients evaluated for coronary artery disease. Circulation 1975; 51: 5-40

21. Ross R: The pathogenesis of atherosclerosis: A perspective for the 1990s. Nature 1993; 362: $801-809$

22. Conti CR, Brawley RK, Griffith LSC, Pitt B, Humphries JO, Gott VL, et al: Unstable angina pectoris: Morbidity and mortality in 57 consecutive patients evaluated angiographically. Am J Cardiol 1973; 32: $745-750$

23. Farhi JI, Cohen M, Fuster V: The broad spectrum of unstable angina pectoris and its implication for future controlled trials. Am J Cardiol 1986; 58: $547-550$

24. Braunwald E: Unstable angina: A classification. Circulation 1989; 80: $410-414$

25. van Miltenburg-van Zijl AJM, Simoons ML, Veerhoek RJ, Bossuyt PMM: Incidence and follow-up of Braunwald subgroups in unstable angina pectoris. J Am Coll Cardiol 1995; 25: 1286-1292

26. Berk BC, Weintraub WS, Alexander W: Elevation of C-reactive protein in 'active' coronary artery disease. Am J Cardiol 1990; 65: $168-172$

27. Grimm RH, Neaton JD, Ludwig W, for the Multiple Risk Factor Intervention Trial Research Group: Prognostic importance of the white blood cell count for coronary, cancer, and all-cause mortality. JAMA 1985; 254: 1932-1937

28. Friedman GD, Klatsky AL, Siegelaub AB: The leukocyte count as a predictor of myocardial infarction. N Engl J Med 1974; 290: 1275 1278

29. Kostis JB, Turkevich D, Sharp J: Association between leukocyte count and the presence and extent of coronary atherosclerosis as determined by coronary arteriography. Am J Cardiol 1984; 53: 997 999

30. de Servi S, Ricevuti G, Mazzone A, Ghio S, Zito A, Raffaghello S, et al: Granulocyte function in coronary artery disease. Am J Cardiol 1991; 68: 64B-68B

31. de Lorgeril M, Latour JG: Leukocytes, thrombosis, and unstable angina (Letter). N Engl J Med 1987; 316: 1161

32. de Servi S, Mazzone A, Ricevuti G, Mazzucchelli I, Fossati G, Gritti $\mathrm{D}$, et al: Clinical and angiographic correlates of leukocyte activation in unstable angina. J Am Coll Cardiol 1995; 26: 1146-1150

33. Gastone G, Serneri N, Abbate R, Gori AM, Attanasio M, Martini F, et al: Transient intermittent lymphocyte activation is responsible for the instability of angina. Circulation 1992; 86: 790-797

34. Kojima S, Nonogi H, Miyao Y, Miyazaki S, Goto Y, Itoh A, et al: Is preinfarction angina related to the presence or absence of coronary plaque rupture? Heart 2000; 83: 64-68

35. Pepys MB, Baltz ML: Acute phase proteins with special reference to C-reactive protein and related proteins (pentaxins) and serum amyloid A protein. Adv Immunol 1983; 34: $141-212$

36. Vigushin DM, Pepys MB, Hawkins PN: Metabolic and scintigraphic studies of radioiodinated human C-reactive protein in health and disease. J Clin Invest 1993; 90: $1351-1357$

37. Liuzzo G, Biasucci LM, Rebuzzi AG, Gallimore R, Caligiuri G, Lanza $\mathrm{GA}$, et al: Plasma protein acute-phase response in unstable angina is not induced by ischemic injury. Circulation 1996; 94: 2373-2380

38. Liuzzo G, Buffon A, Biasucci LM, Gallimore JR, Caligiuri G, Vitelli A, et al: Enhanced inflammatory response to coronary angioplasty in patients with severe unstable angina. Circulation 1998; 98: 23702376

39. Biasucci LM, Liuzzo G, Caligiuri G, van de Greef W, Quaranta G, Monaco C, et al: Episodic activation of the coagulation system in unstable angina does not elicit an acute phase reaction. Am J Cardiol 1996; 77: $85-87$ 